\title{
Manual for designing community based interventions for preventing postpartum hemorrhage (PPH) using misoprostol: Standardized pilot-test training manual
}

\author{
Saumya RamaRao \\ Population Council \\ Tekle-Ab Mekbib \\ Population Council \\ Sarah Raifman \\ Population Council
}

Follow this and additional works at: https://knowledgecommons.popcouncil.org/departments_sbsr-rh

Part of the Demography, Population, and Ecology Commons, Family, Life Course, and Society Commons, Gender and Sexuality Commons, International Public Health Commons, Maternal and Child Health Commons, Medicine and Health Commons, and the Women's Health Commons How does access to this work benefit you? Let us know!

\section{Recommended Citation}

RamaRao, Saumya, Tekle-Ab Mekbib, and Sarah Raifman. 2009. "Manual for designing community based interventions for preventing postpartum hemorrhage (PPH) using misoprostol: Standardized pilot-test training manual." Washington, DC: Population Council. 


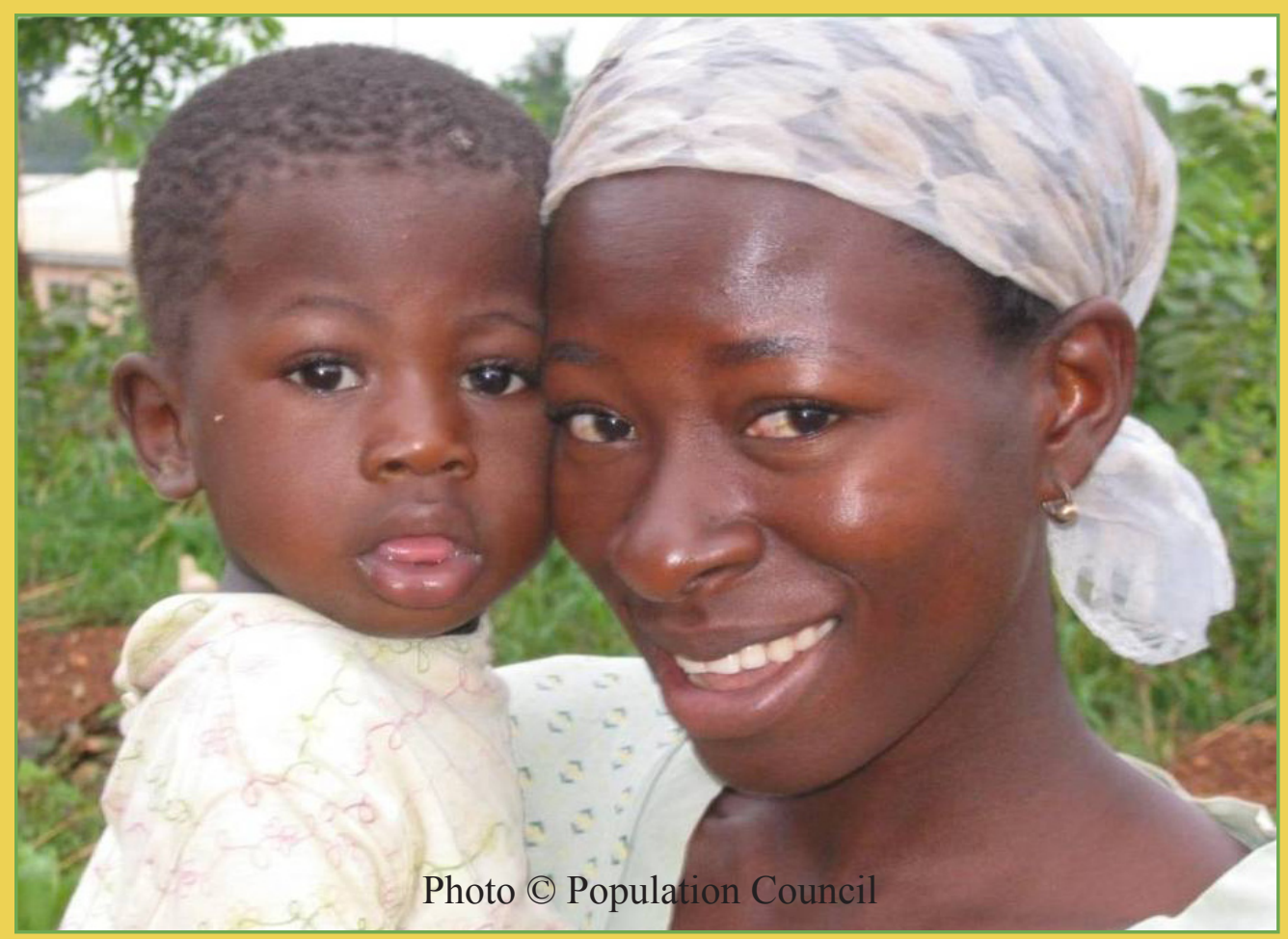

\section{Manual for Designing Community Based Interventions for Preventing Postpartum Hemorrhage (PPE)) using Misoprostol}

Standardized Pilot-Test Training Manual

September 2009

Saumya RamaRao, Tekle-Ab Mekbib, and Sarah Raifman 


\section{List of Acronyms}

AMTSL - Active Management of the Third Stage of Labor

CCT- Controlled Cord Traction

CFR-Code of Federal Regulations

EmOC - Emergency Obstetric Care

FDA-Food and Drug Administration

FIGO- International Federation of Gynecology and Obstetrics

GCP -Good Clinical Practice

HIV- Human Immunodeficiency Virus

ICM-International Confederation of Midwives

IEC-Information and education Communication

IRB-Institutional Review Board

Mcg- Microgram

MDG- Millennium Development Goals

POPPHI - Prevention of Postpartum Hemorrhage Initiative

PPH - Postpartum Hemorrhage

RH- Reproductive Health

SOP - Standard Operating Procedures

SAEs/AEs - Serious Adverse Events, Adverse Events

UNFPA - United Nations Population Fund

UNICEF - United Nations Children's Fund

WHO- World Health Organization 


\section{Table of Contents}

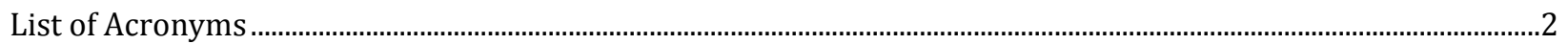

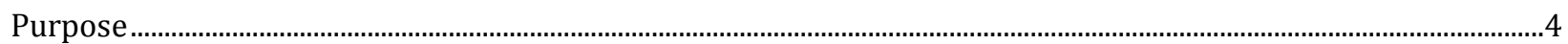

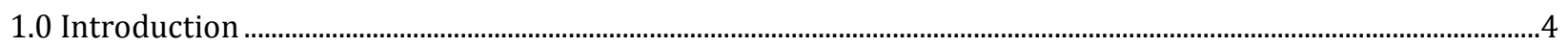

2.0 Implementing a prevention program for PPH using misoprostol ……..................................................................

3.0 Population Council Intervention Protocol and Policy …………………………………...............................................15

4.0 Monitoring, Evaluation and Research ………………………….............................................................................. 17

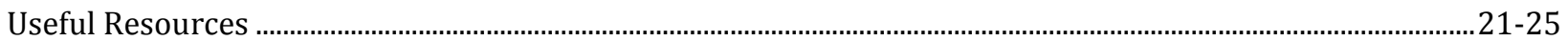

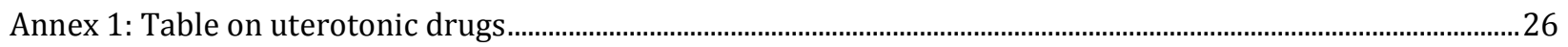

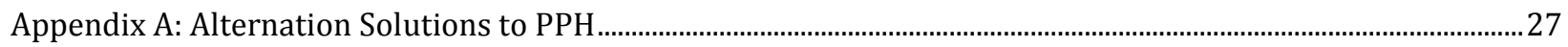

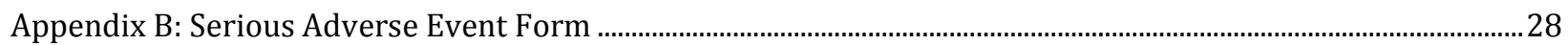

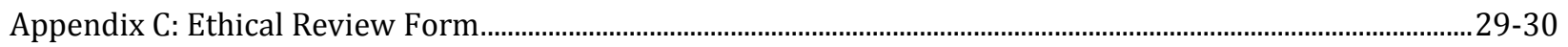

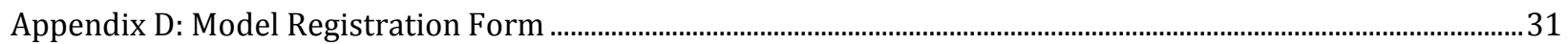

Appendix E: Illustrative Domains for Data Capture...........................................................................................................32-33 
The purpose of this manual is to provide a comprehensive step-by-step standardized guide for Population Council staff on how to design and implement community-based pilot interventions for the prevention of postpartum hemorrhage, using the inexpensive and easily accessible drug misoprostol that does not require special storage facilities such as refrigeration. This manual includes an introduction and background section that explains basic information about maternal mortality, normal and abnormal pregnancy, and postpartum hemorrhage. This section also describes the prevailing methods of prevention and treatment for postpartum hemorrhage, Active Management of Third Stage of Labor (AMTSL) and the steps it includes, as well as the use of misoprostol for the prevention and control of postpartum hemorrhage.

The second half of the manual focuses on how to develop a protocol for an intervention study on misoprostol, by providing information on who will do what, where, and when. It includes steps on submitting the research protocol including informed consent to the IRB for approval, and developing training modules (identifying sites and community-based workers and designing data collection forms). Lastly, the manual explains the importance of monitoring and evaluation, data collection and review, preparation for the conduct of a rigorous study following Good Clinical Practice (GCP), and analysis and report-writing. This manual is intended for use by Population Council staff with suitable modification to fit the context of their study community and stakeholders.

\subsection{Introduction}

Postpartum hemorrhage (PPH) is one of the largest contributors to maternal morbidity and mortality and accounts for nearly one quarter of all maternal deaths worldwide (WHO, 2009). Figures released in 2007 by UNFPA, WHO, UNICEF, and the World Bank indicate that women continue to die of pregnancy-related causes at a rate of about one a minute (UNFPA, 2007). In most developing countries, the majority of deliveries are conducted by unskilled birth attendants within the home. In such low-resource settings, the administration of the uterotonic drug, misoprostol, offers an alternative to other standard preventions and treatments for $\mathrm{PPH}$.

Due to the fact that many births take place outside of the health system, this intervention model aims to utilize already existing and trusted social structures within the community to manage PPH through the distribution of misoprostol, accompanied by community and family education. Each community will have varying resources, community structures, and health systems; therefore, Population Council staff will need to adapt use of this manual's guidelines to the intervention model accordingly.

This manual has been compiled for Population Council staff, who contribute to service delivery projects within the Reproductive Health program. Staff with all degrees of training and experience in reproductive health, both medical and non-medical, may benefit from this manual, and all are encouraged to review it. 


\subsection{Understanding PPH}

\section{What causes postpartum hemorrhage (PPH)?}

Although many medical conditions can cause hemorrhage, the majority of severe bleeding during childbirth occurs because the uterus is unable to contract properly after delivery of the baby. Excessive bleeding can also be caused by tears in the vagina and cervix, clotting disorders, and small pieces of the placenta that remain attached. While some bleeding is expected after childbirth, blood loss greater than $500 \mathrm{ml}$ during the first 24 hours postpartum is commonly defined as a marker for PPH (PATH, 2005-2007). A woman may die from PPH within two hours if she does not receive immediate and adequate medical care. The speed with which death occurs presents a major challenge to health systems in rural areas of developing countries, where there is often poor communication, transportation and shortages of necessary drugs and equipment, among other limitations.

\section{Who suffers from PPH?}

Certain factors are associated with developing $\mathrm{PPH}$, such as prolonged third stage of labor; pregnancy-induced hypertension; mediolateral episiotomy; previous $\mathrm{PPH}$; twins or previous multiple pregnancies; early detachment of the placenta from the uterus; soft-tissue lacerations; use of forceps or vacuum-assisted delivery; infection; and obesity (Combs et al 1991). However, most cases of PPH (roughly two-thirds) take place in women with no known risk factors (Gynuity Health Projects). This is why ALL women must have access to prevention during pregnancy and to emergency treatment at the time of delivery for severe blood loss.

\section{How can we prevent and treat PPH?}

Fortunately, most cases of PPH can be prevented with appropriate care. Furthermore, existing methods of management and prevention are simple and inexpensive. What is needed to manage PPH is a skilled birth attendant, who can recognize the onset of PPH, stabilize the woman, and refer to a higher-level facility or administer the treatment him/herself. In low-resource settings particularly, efforts should focus on preventing and managing cases of PPH before higher-level care (blood transfusion, surgery, and/or intravenous therapy) is needed. The prevailing method for preventing and treating PPH is Active Management of the Third Stage of Labor (AMTSL). Oxytocin is the ideal and most effective drug to use with AMTSL when available. However, oxytocin requires proper storage conditions such as refrigeration, which may not be available in rural communities. Other ways of managing PPH have also been studied (see Appendix A). 


\section{Benefits to PPH Prevention}

$\rightarrow$ Decreases maternal mortality and contributes to meeting MDG \#5

$\rightarrow$ Exposes attendants to less blood (thus reducing risk of infection from HIV or other blood-borne diseases)

$\rightarrow$ Decreases the number of bloodstained materials to throw away or clean

$\rightarrow$ Uses less oxytocin and other supplies than would be required by a case of PPH, and

$\rightarrow$ Less time is spent waiting for delivery of the placenta-leaving more time to attend to the newborn and for the mother to rest and hold her baby immediately after the birth.

\subsection{Understanding AMTSL}

Active Management of the Third Stage of Labor (AMTSL) is promoted by the World Health Organization, United Nations Children's Fund, United Nations Development Fund, FIGO, ICM, and other international organizations. AMTSL consists of three active methods of prevention, which cause the uterus to contract and speed the delivery of the placenta, thereby reducing the potential for bleeding. By contrast, during Expectant Management of the third stage, the woman does not receive drugs, the cord is clamped later, and the placenta is expelled naturally by the mother's efforts.

\section{$\underline{3 \text { Components of AMTSL } 1}$}

1. Administration of a uterotonic drug, preferably oxytocin, within one minute of childbirth to cause the uterus to contract;

2. Controlled traction of the umbilical cord with counter pressure to the uterus, which supports and stabilizes the uterus; and

3. Massage of the uterus through the abdomen after delivery of the placenta to keep the uterus well contracted and prevent further blood loss. ${ }^{2}$

\subsection{Understanding Uterotonics}

There are several different types of uterotonic drugs that play a critical role in both prevention and treatment of PPH. The relative advantages and disadvantages of these different drugs and potential side effects have been an important topic of research for the prevention of PPH (See Annex 1).

\footnotetext{
${ }^{1}$ Source: MAQweb: http://www.maqweb.org/techbriefs/tb48posthem.shtml

${ }^{2}$ For more detail on the three core components of AMTSL, visit Maqweb (http://www.maqweb.org) or POPPHI (http://www.pphprevention.org/resources.php).
} 
Since 1996 misoprostol has

been used for the control of PPH; originally, it was used in the treatment of peptic ulcer.

In conjunction with

mifepristone it can also be used for the medical induction

of abortion. Its use as an induction agent for abortion has meant that misoprostol

has faced considerable

political opposition to its

widespread use for preventing and controlling

PPH.
Oxytocin: posterior pituitary extract

Mechanism: Stimulates a contraction of smooth muscle in the uterus by increasing intracellular calcium, which mimics contractions of normal labor and consequently temporarily decrease uterine blood flow.

\section{Ergometrine: preparation of ergot}

Mechanism: Directly increases the force and frequency of uterine contractions, which helps expel the placenta and puts pressure on the blood vessels to contract. Also, through a second action, it directly promotes contraction of the arteries in the body, which causes the blood vessels in the uterus to constrict.

Syntometrine: combination of oxytocin and ergometrine

Mechanism: Combination of mechanisms of ergometrine and ocytocin.

Misoprostol: prostaglandin E1 analogue

Mechanism: Mimics prostaglandin and acts directly on the muscle cells of the uterus causing contraction of the uterine muscle. Also causes the cervix to soften, which allows the placenta to be expelled more easily.

\section{Which Uterotonic is best?}

Skilled attendants should offer oxytocin, when available, in preference to ergometrine, syntometrine, and misoprostol. However, in rural low-resource settings, the use of misoprostol is recommended because of its stability (heat and light) and easy storage and administration. Misoprostol is administered in tablet form, either sublingually or vaginally (usually in $200 \mathrm{mcg}$ tablets). By contrast, ocytocin is administered via IV or IM injection only, which requires proper equipment and personnel. Similarly, ergometrine and syntometrine (erogmetrine combined with oxytocin are effective only through IM injection (the oral form is ineffective). FIGO and ICM have endorsed the use of misoprostol for the prevention of PPH in settings where oxytocin is not available or birth attendants' skills are limited (WHO: ICM/FIGO Joint Statement, 2003). Further research is being done to determine misoprostol's effectiveness relative to oxytocin and its most efficient dosage and route of administration (Hofmeyr et al 2005). ${ }^{3}$

\footnotetext{
${ }^{3}$ In some settings there will be no uterotonics available. According to the International Confederation of Midwives (ICM) and the International Federation of Gynecology and Obstetrics (FIGO), management of the third stage of labor in the absence of uterotonics includes the following components: 1) waiting for signs of separation of the placenta (cord lengthening, small blood loss, uterus firm and globular on palpitation at the umbilicus); 2) encouraging maternal effort to bear down with contractions and, if necessary, to encourage an upright position; 3) controlled cord traction is not recommended in the absence of uterotonic drugs, or prior to signs of separation of the placenta ( as this can cause partial placental separation, a ruptured cord, excessive bleeding and uterine inversion); and 4) uterine massage after the delivery of the placenta is appropriate.
} 


\section{What is the recommended dosage and administration of misoprostol?}

According to Blum et al, 2007, in settings where no other uterotonic agents are available, 600 micrograms of misoprostol can be used for the primary treatment of PPH (the WHO recommends a dose between 200 and 800 micrograms $^{4}$ ). The misoprostol can be given either orally or sublingually. Sublingual use might be helpful when women are unconscious or under anesthetic. The recommended dose for PPH treatment, $600 \mu \mathrm{g}$, should never be given prior to the delivery of the baby. This is especially important in settings where there may be unidentified twin pregnancies. Additionally, misoprostol should not be used for PPH treatment if it was already given for PPH prevention within the last 2 hours (Blum et al, 2007). Further research is needed to more accurately determine the smallest dose that is effective and safe. In a recent Cochrane review, researchers concluded that 400 micrograms of misoprostol were found to be safer than $\geq 600$ micrograms and just as effective (Hofmeyer et al, 2009).

\section{What are the precautions to providing misoprostol to patients 5 ?}

- If possible, ensure that the patient does not have a history of allergy to misoprostol or other prostaglandins.

- Providers should confirm that there is no undiagnosed second twin before giving misoprostol. If uncertain, the provider should wait until after the placenta is delivered before giving the misoprostol.

- Small amounts of misoprostol or its active metabolite may appear in breast milk, but no adverse side effects on nursing infants have been reported.

\section{What are the effects and side-effects of taking misoprostol ${ }^{6}$ ?}

The side effects associated with misoprostol are transient and non-fatal. Prolonged or serious side effects are uncommon. However some combinations from the list of side effects below have been reported after the use of misoprostol.

- Shivering - Shivering is the most common side effect and usually occurs within the first hour of taking misoprostol. The side effect will subside 2-6 hours after delivery. According to studies (Hoj et al, Walraven et al and Derman et al), chills were reported in $32 \%-57 \%$ of women receiving misoprostol.

- Fever - Fever is less common than shivering and does not necessarily indicate infection. Elevated body temperature is often preceded by shivering, peaks 1-2 hours after taking misoprostol and usually subsides within 2-8 hours. An antipyretic can be used for relief of fever. If fever or shivering persists beyond 24 hours, the woman should seek medical attention.

- Diarrhea, Nausea, and Vomiting - Diarrhea may occur after the administration of misoprostol but should resolve within a day. Nausea and vomiting may occur as well and should resolve 2 to 6 hours after taking misoprostol. An antiemetic may be used if needed and if available.

- Cramping - Cramping or painful uterine contractions, as is common after childbirth, may begin as early as 30 minutes after misoprostol is administered. Non-steroidal anti-inflammatory drugs or other painkillers can be used for pain relief and do not affect the success of the massage prevention method.

\footnotetext{
${ }^{4}$ WHO, 2009.WHO Statement regarding the use of misoprostol for postpartum haemorrhage prevention and treatment. Department of Reproductive Health and Research.

${ }^{5}$ Source: Census Statement, 2004

${ }^{6}$ lbid
} 
- Postpartum bleeding - Excessive bleeding before or after placenta delivery should be referred immediately for additional care. Additional misoprostol should not be given within six hours of the initial dose.

\section{Where is misoprostol approved and available?}

Misoprostol was originally approved in the U.S., where it was marketed and distributed as Cytotec. A number of countries have now approved misoprostol for its use in preventing PPH, foremost among which is India. More than a dozen countries are now planning to or are in the midst of introducing misoprostol for PPH prevention and several pharmaceutical companies are pursuing dedicated PPH products. Misoprostol is available in: Bangladesh, Brazil, Colombia, Egypt, France, Gambia, India, Indonesia, Korea, Nigeria, Russia, Taiwan, Tanzania, the U.S., and Vietnam and recently registered in Pakistan. Misoprostol is now included on the World Health Organization Model List of Essential Medicines for its incomplete abortion indication, as of March 2009 (WHO 2009).

\subsection{Implementing a prevention program, using misoprostol}

\subsection{Purpose}

Most births in low resource settings occur at home and the majority of the communities in which Population Council staff is working already include existing systems of community-based workers. The purpose of this intervention, therefore, is to equip community-based workers with the skills to prevent PPH in rural communities with the use of misoprostol. The goal of emergency obstetric care at the primary care level is to diagnose the problem, stabilize the woman, and arrange for transport to the nearest facility capable of managing and treating the complication. With the use of misoprostol, community-based workers will, for the most part, be able to manage PPH at the primary health care level.

\subsection{Objectives}

1. Develop a training guideline for community-based workers, their supervisors and medical providers for the administration of misoprostol;

2. Implement the program in adherence with good clinical practice and quality and ethical research, and in compliance with applicable regulations

3. Monitor the feasibility of misoprostol delivery through community-based workers;

4. Document the experience of the program using rigorous evaluation methods; and

5. Demonstrate the advantages of using misoprostol in the prevention of PPH

\subsection{Origins and References}

This training guide is modeled after two intervention studies that were designed by the Population Council to test the delivery of misoprostol and the feasibility of home administration of misoprostol for PPH through 
community initiatives in rural Ethiopia (Mekbib et al 2009, Population Council) and Pakistan (Mir et al., 2009). Community structures (on which to base a network of community-based workers) will vary from place to place, but the training process for community workers on the use of misoprostol presented in this manual should be applicable and adaptable. This document was compiled with the aid of additional information from individual social science and biomedical researchers as well as international organizations contributing to maternal health, such as the World Health Organization (WHO), Gynuity Health Projects, FIGO, ICM, Venture Strategies for Health and Development, PATH, JHPIEGO, and others.

\subsection{Implementation Steps}

\section{Identify community-based workers to participate in training}

Population Council staff should choose community-based workers from the community, if possible from existing community systems and structures, which are trusted by families and mothers. These workers may be located outside of the health system or they may serve as links between the health system and the community. For example, in Ethiopia (Mekbib et al 2009), the intervention is designed around mentors already involved in an existing program for married adolescent girls implemented in rural areas of the Amhara region. The mentors are community-based workers who are already trained in mobilizing married adolescent girls at the household level. In Pakistan (Mir et al 2009), the intervention is designed around community workers and care providers (dais and Lady Health Visitors) who have previously been involved in health related projects within the community. Family members and next of kin may also be present at deliveries. In this study, more than 2000 dais had been trained by the USAID-funded PAIMAN project (a maternal health intervention) in ten districts. Additionally, the Lady Health Visitors, who are trained as paramedics, accompanied the social scientists from house to house for patient recruitment and provided backup support to the dais in case of emergencies. In both of these examples (Ethiopia and Pakistan), the intervention is designed around existing systems of community-based workers already involved in the community.

\section{Role of Community-Based Workers:}

- Identify all pregnant women in the area

- Make home-visits to the pregnant woman (the number of planned visits should be decided by the PI, depending on the country setting)

- Provide information to pregnant women about nutrition, immunization, planned births, breast care and the importance of breastfeeding

- Provide information about danger signs by informing pregnant women about fever, bleeding, swelling of the legs and hands, convulsions etc. and the need to seek medical care when these signs occur

- Discuss how to prevent PPH during home visits

- Make arrangements to be called when labor starts

- Distribute misoprostol to women who live far away shortly before delivery, in the case that community-based workers cannot be present at the delivery; otherwise provide misoprostol while observing normal deliveries

- Store misoprostol at room temperature in an enclosed container and protected from humidity and excess heat 
- Discuss misoprostol storage with pregnant women

- Observe the delivery of women who haven't given prior consent to participate in the project without administering misoprostol, and provide the necessary support during and after delivery

- Conduct postpartum home visits to determine maternal and newborn outcomes

- Conduct interviews during postpartum home visits to find out about misoprostol use, experience of side effects, and to retrieve unused misoprostol

- Arrange referral immediately for cases that develop obstetric complications, including PPH, to the nearest health facility

- Cover the costs for transportation for those who cannot afford the expenses (with allotted funds from the project)

- Follow referral cases in health facilities to find out the mother's health condition

- Recognize, record and report Adverse Events/Serious Adverse Events

- Identify and make arrangements with the referral facility that offers comprehensive emergency obstetric care (CEmOC)

\section{Role of health workers/supervisors:}

- Supervise and oversee the work of community-based workers

- Maintain misoprostol stock and records

- Replenish misoprostol when the need arises

- Monitor the safety of the drug as per the MOH guidelines

- Store misoprostol at room temperature, in an enclosed container and protected from humidity and excess heat

- Provide logistic support to referral cases.

\section{Linking with the health system}

It is very important that an intervention which uses community-based workers as the primary mode of delivery of misoprostol is clearly "linked" with the existing health system in the community. Linking the community-based worker with the health system is essential to the overall effectiveness and sustainability of the program. The roles and responsibilities of both the health system and the community-based worker should be mutually discussed and agreed upon with clear definitions and conveyed to each group. At the programmatic level, it is the duty of each individual Population Council project team (led by the PI) to ensure that these dialogues take place between the health system and the community structures.

Community-based workers involved in the intervention must be aware of which health facilities are available, what services they provide, when they are available, and where they are located within the community. They must also coordinate with these health facilities and confirm their cooperation. In return, the health system must provide the necessary support to community-based workers, in the form of permission and authority, supplies, resources, and time. Both the health system and the community structure should acknowledge each other's goals and guidelines.

Pilot-test training program for community-based workers 
Training will be provided to birth attendants/community-based workers on misoprostol distribution and misoprostol-related counseling issues (e.g., time of tablet intake, risk of mistimed intake or of taking more than 600 micrograms, benefits of misoprostol, probable side-effects of misoprostol, when to go to the hospital even after taking misoprostol, dangers of delay in reporting to hospital, among others). Basic education on pregnancy and delivery and the magnitude of maternal deaths due to PPH will also be included. A model training course, based on a training manual developed for the delivery of misoprostol for PPH through community initiatives in rural Ethiopia, is provided below that could be adapted for each study.

After training, community-based workers will be able to:

a. Mobilize communities to utilize services available within the health system

b. Provide information to pregnant women about birth preparedness and on how to prevent PPH

c. Provide women with misoprostol immediately after the delivery of the baby and before expulsion of the placenta

d. Arrange referrals for cases of abnormal bleeding or those having other obstetric complications

e. Conduct interviews after the completion of the delivery, and register delivery outcome in the logbook

f. Follow referred women with complications by going to the health facility and getting feedback to register in the log book

g. Note Adverse Effects (AEs) and Serious Adverse Effects (SAEs) for reporting to program staff. (Examples of AEs and SAEs are provided under 4.2 Process Evaluation on page 19)

\section{Community Sensitization and Counseling}

Once trained, community-based workers will orient families on safe motherhood practices and the use of misoprostol for the prevention and management of PPH. Households will be sensitized on the importance of accessing the community-based workers at the time of delivery, so that misoprostol can be administered and the delivering mother observed. Unexpected complications that can occur during routine delivery will be discussed. The need for arranging transport to a nearby health facility in the case of complications will also be discussed. If possible, efforts will be made to draw action plans on community supported emergency transportation.

\section{Enrollment of Pregnant Women}

Community-based workers will identify pregnant women in the community and provide them with the necessary information for voluntary enrollment in the intervention. Population Council staff will verify informed consent (Appendix B). Women enrolled in the project will be visited at least four times before delivery, observed during delivery and provided with misoprostol at the time of delivery. When a community-based worker arrives at the house of a woman who did not give consent for participation, the community-based worker will observe the delivery without administering misoprostol and continue observation during the postpartum period. (The PI will pay attention to situations such as these and discuss with in-country partners about ways for addressing such situations.) In the case of emergency, community-based workers will contact health care providers and/or health extension workers for assistance and possible transport to a health facility. Community-based workers should also keep modest funds in case transport of women is needed. The participating pregnant women will be provided with three tablets of misoprostol (i.e. $200 \mathrm{mcg}$ each) in case a community-based worker is absent during delivery. The point at which these tablets are delivered during pregnancy should be determined within 
the specific community context, given the varying local needs of the women. Maximum care is taken to avoid the swallowing of the misoprostol tablets by the pregnant woman before delivery.

\subsection{Training Program for Community-Based Workers}

Given that misoprostol is a relatively new drug used for the prevention of PPH, many trained medical providers may also benefit from this brief training course on the benefits of misoprostol, its probable side effects, risk of mistimed intake, and relative effectiveness to other uterotonics. While this manual emphasizes the distribution of misoprostol through non-medical community workers, it is important that health providers are aware and knowledgeable about the drug and, in particular, how to respond if emergency medical attention is needed.

Specific training courses for local community-based workers should be developed by the program supervisor in each region, with specific regards to the knowledge level of the workers, the needs of the community, and the resources available for the training. It is recommended that the training course be four days long, with individual sessions ranging from 30 minutes to 90 minutes, depending on the topics to be covered. The methods used during each training session should be a combination of discussion, lecture, and demonstration, and occasionally role play (when helpful). Before training begins, supervisors should have communication, transportation, and distribution systems set in place for the intervention.

\section{Guideline for training sessions:}

\section{Session I: Introduction to Training}

Welcome participants, hand out a participant package with necessary forms and information, and conduct introductions. Establish expectations and goals for the training course. Solidify the training schedule and ensure participants' commitment. If an evaluation of the training is planned, it will be useful to have a pretraining measure of participant knowledge to measure change over the training program.

\section{Session II: Magnitude of maternal death and sickness, globally and regionally}

Define the terms maternal mortality and maternal morbidity and explain the magnitude of the problem, globally, regionally and locally. The trainer should explain the complications during pregnancy or childbirth that can lead to maternal death (direct and indirect causes), in addition to the predisposing factors in the region.

\section{Session III: Danger signs during pregnancy and childbirth}

The trainer should explain what the term "danger sign" means and discuss the danger signs associated with pregnancy, including bleeding, fever, severe abdominal pain, severe headache, swelling of face/hands/feet, vaginal discharge with offensive smell, excessive vomiting, convulsions/fits, rupture of membranes, reduced/absence kicking, etc. It should be emphasized that if these dangers signs are experienced, a woman has to go immediately to the nearest health facility to get appropriate care.

\section{Session IV: Stages of Labor}

During this session, the trainer may use a pelvic model to show basic anatomic sites and how pregnancy, labor and normal delivery takes place. The trainer should also explain the first, second, third and fourth stages of labor, as well as the time intervals of each period. Also explain and demonstrate external uterine 
massage (on a model), in preparation for the next session's discussion of AMTSL. In this session, it may help to show a video that documents normal delivery.

\section{Session V: Theoretical understanding of physiologic and active management of the $3^{\text {rd }}$ stage of labor}

The trainer should discuss the components of physiologic/expectant management of the third stage of labor and active management of the third stage of labor. Emphasize that AMTSL is the predominant method of managing PPH and explain the advantages of AMTSL over expectant management.

\section{Session VI: Postpartum hemorrhage}

Explain the definition of PPH, the global impact of PPH on maternal health, the causes of PPH (cervical and vaginal tears, retained placenta, and uterine rupture), and the methods of prevention of PPH. The trainer should discuss the specific role the community-based health workers will play in managing PPH within the community.

\section{Session VII: Uterotonic drugs}

Discuss uterotonics in general and the use of misoprostol more specifically. The trainer should emphasize the safety, acceptability, and feasibility of the community-based PPH prevention mechanism using misoprostol. Discuss the appropriate and safe dosage of misoprostol and when it should be administered (directly after the delivery of the baby). The trainer and community-based workers should establish a system for distribution of misoprostol within the community, and articulate the specific role of the community-based workers in that delivery. ${ }^{7}$

\section{Session VIII: Community sensitization and Counseling}

In this session, the trainer and participants should discuss the benefits of community sensitization and family counseling. ${ }^{8}$ Sensitization and counseling should cover the following topics: unexpected complications; how to recognize PPH; how and when to administer misoprostol; the need for arranging transportation; and the importance of assessing the community-based workers at the time of delivery. A role playing exercise may be useful during this session. Brainstorm ways to deal with challenges associated with cultural, religious, and political customs or beliefs of community members.

\section{Session IX: Enrollment and Receiving Consent}

Trainer discusses the purpose of the study and the processes to be followed to receive consent from clients. Discuss the need for explaining the risks and benefits of taking misoprostol to potential participants before they give consent. Also discuss topics including, compensation, voluntary participation in the study, and confidentiality.

\section{Session X: Record Keeping}

\footnotetext{
${ }^{7}$ Community-based workers will carry with them a small supply of misoprostol to home deliveries (enough misoprostol for up to two deliveries is suggested). In the case that they are unable to be present for the delivery, it is recommended that 3 tablets of misoprostol be provided to the family/mother within the last month of gestation (around week 32). At this time, community-based workers should carefully remind mothers and families that misoprostol should not be taken before the delivery.

${ }^{8}$ Community sensitization empowers women by educating them, encouraging them to ask for help, and providing them with the tools to help themselves. It also educates family members about how to help and be supportive.
} 
The trainer should discuss the importance of monitoring and evaluation for the project and the role of the community-based workers in good record keeping. A process of formal registration for the program should be established as well as a method for recording data.

\section{Session XI: AE and SAE Reporting}

In this session, the trainer will explain the purpose of clinical trial Drug Safety Monitoring/Pharmacovigilance. He/she will provide and explain the definition of an AE and SAE. He/She will review the procedure of collecting and reporting AEs/SAEs. The trainer will explain the regulatory requirement in Drug Safety/Pharmacovigilance.

\section{Session XII: Referral for PPH and other obstetric complications}

This session should cover the steps for conducting a referral to be followed by community-based workers. The reasons for and importance of referral should be explained to all participants. During this session, it would be helpful to use a regional map to plot out the health facilities available in the area.

\section{Session XIII: Community mobilization}

Define community mobilization and explain the reasons for mobilizing the community. Participants and trainers should pinpoint ways of mobilizing community members and enhancing their participation. The group should leave this session with a good understanding of what factors promote or hinder effective community mobilization for PPH prevention within the particular community. (Note: group discussions may be effective in defining methods for community mobilization).

\section{Session XIV: Organizing home visits}

This session is devoted to understanding the purpose of a home visit and planning on how to execute home visits. The trainer should discuss the need for obtaining permission for community leaders and local officials, as well as the sensitivity required while conducting home visits. The goals of each home visit should be articulated and guidelines for appropriate behavior defined.

At the end of the training sessions, it may be useful to ask participants to complete an evaluation form. This will help ensure that time is used efficiently and that the topics covered are appropriate for the level of knowledge of the community-based workers.

\subsection{Population Council Guidelines and Policies}

The goal of this section is to provide guidance for following Council procedures. The order of tasks for developing, implementing and evaluating an intervention based on the Council's guideline policies is provided below.
Population Council Intervention Guidelines

1. Preparation

2. Develop a Study Protocol

3. Study Protocol Submission to IRB

4. Training of Program Staff

5. Intervention

6. Research

7. Analysis and Dissemination of reporting 


\subsection{Preparation}

It is essential to ensure that there is sufficient funding for the project before beginning to develop the protocol or submitting it for IRB approval. Project implementers should hold discussions with national stakeholders to assess the level of interest and support for a project of this nature and scale. Staff should also review relevant national policies and guidelines to determine current policies for misoprostol use, mechanisms for procurement, and the range of stakeholders. In order to prepare a proposal, it will be necessary to have considered all the key elements involved in the intervention (as discussed in section 2.0 of this manual) and the overarching goals and indicators for evaluation. The development of a tentative budget is helpful in determining how much funding will be necessary for the study.

\subsection{Develop Study Protocol}

The study protocol-including a description of the intervention, a study design, ethical procedures to be followed, and a description of Good Clinical Practice standards-must be developed before any implementation begins. The protocol should include detailed information on informed consent for the study (how many types of consent forms will be written, for whom, and at how many and which points in the intervention) as well as information on good clinical practice and safety monitoring.

\section{Informed Consent and Confidentiality}

All information collected from a pregnant woman who agrees to participate in this project will remain strictly anonymous and confidential. Her name will not be recorded on any questionnaire forms, so there will be no way to link her name to her answers. In this intervention, the privacy of participants must be respected. Moreover, written results and reports will not include any details about intervention subjects that could identify them. If a pregnant woman agrees to participate in this project, she does not have to answer any questions she does not want to, and she may ask clarification from the service provider whenever she wishes. The data collected will be available only to the research staff, and all completed questionnaires and reporting formats will be stored in locked cabinets.

Prior to any involvement in this intervention, pregnant women will be given a brief description of the aims of the project. Pregnant women who agree to participate in this project will be provided misoprostol immediately after delivery, free of cost. This drug will be provided by trained communitybased workers from the community. Informed consent forms should be prepared for each intervention and will be read slowly and carefully to each participant (mother and any other active participant) in the local language. Consent should be obtained from all participants when they register for the study and again when they approach delivery (at 6 months and 8 months).

Informed consent forms should include: study purpose; procedure to be followed; risks and benefits; compensation; voluntary participation; confidentiality of responses; and demonstration of consent. The informed consent forms should emphasize key aspects of respect (regarding the participant's autonomy and right to choose), beneficence (the program minimizes risks and maximizes benefits), and justice (the intervention is designed specifically for this community and is intended to benefit the participants and should not discriminate on the basis of socioeconomic status, educational level, etc). If a pregnant woman chooses to participate in this intervention, she will be required to sign the Informed Consent Form and her involvement will entail answering a number of questions about herself. However, if a pregnant woman cannot sign, a verbal consent will be recorded and witnessed by an appropriate witness. 


\section{Good Clinical Practice and Safety Monitoring}

When designing a community-based program for the prevention of postpartum hemorrhage using misoprostol, consult and discuss with the Reproductive Health Program Director whether or not the intervention to be implemented will be a clinical study. The intranet provides guidance on what will be considered a clinical study; see https://popinsider.popcouncil.org/2507 3416.htm. If the intervention is deemed to be a clinical study, it must closely follow the guidelines for Good Clinical Practice (GCP).

Good Clinical Practice is an international ethical and scientific quality standard for designing, conducting, recording and reporting studies that involve the participation of human subjects. Compliance with this standard provides assurance that the rights, safety and well-being of study subjects are protected, consistent with the principles that have their origin in the Declaration of Helsinki, and that study data are credible and accurate.

Partners in GCP are: Regulatory agencies; Sponsors/Contract Research Organizations (CRO); Institutional Review Boards (IRB)/Institutional Ethic Committees (IEC); Investigators; and Subjects.

GCP for the Population Council has three main components: 1) regulations enforceable by law (U.S.based Code of Federal Regulations [CFR]); 2) guidelines, generally accepted practices, but not enforceable by law; and 3) national laws of the country. The CFR consists of various regulations concerning clinical research, issued by government agencies and departments. Other governments, research sponsors, and IRBs often have additional requirements to those established for conducting research in the U.S. Research sponsors must work with international regulatory agencies when conducting research outside of the U.S., to be sure that both U.S. and country-specific regulations are met. Other topics covered by FDA guidelines for GCP are informed consent, IRB operations, emergency use of investigational treatments, confidentiality, and compensation for research-related injuries. ${ }^{9}$

The standards that make up GCP apply to all aspects of clinical research, from designing a study protocol (process) to reporting the research findings (results). Other standards that may apply to the conduct of clinical research include the implementing site's standard operating procedures (SOPs). SOPs are detailed, written instructions used to achieve uniformity of the performance of a specific function (International Conference on Harmonisation). They are necessary for clinical research to achieve maximum safety and efficiency. Included in the standard operating procedures for PPH prevention with misoprostol, for example, should be a detailed protocol for reporting serious adverse events (SAEs) and adverse events (AEs). More information on AEs and SAEs is provided in section 4.0. Appendix B provides an illustrative form for recording AEs and SAEs. More generally, SOPs require a certain level of scrutiny and assessment of the quality of a product before it is used.

\subsection{Study protocol submission to IRB}

\footnotetext{
${ }^{9}$ There is significant overlap between GCP and IRB requirements. IRB review of research must include consideration of similar criteria to ensure the well-being of study participants and accuracy of the data (i.e. informed consent, risk/benefit analysis, screening activities, data safety monitoring, and privacy and confidentiality).
} 
The Institutional Review Board is a committee that has been formally designated to approve, monitor, and review biomedical and behavioral research involving humans, with the aim of protecting the rights and welfare of the research subjects. IRB approval is required for this intervention, from both the Council's IRB as well as the IRB of the country in which the study is being implemented. A copy of the Ethical Review Form that must be completed for all protocols supported by the Population Council is included as Appendix C.

The following steps in the Population Council's intervention guidelines include training of program staff; implementation of the intervention; research; and, analysis and dissemination of reporting. These tasks must follow the needs, requirements, and guidelines of each specific study location. Through each step of the process, ensure that senior Population Council staff will be available for technical support and guidance.

\subsection{Monitoring, Evaluation and Research}

In this section, we provide an illustrative set of activities and guidelines for monitoring, evaluation, and research. Staff involved in monitoring and evaluation include the PI, the field supervisor, and study coordinators, among others. For example, all field level activities will be coordinated by one field supervisor, who will be supported by a trained study coordinator at each intervention site. Research investigators will undertake regular field visits and will participate in all supervision and monitoring activities.

A number of tools will be required to record data, including a registration form to list and enroll pregnant women in the program (Appendix D) and a daily register that documents the community-based workers' contacts and content related to maternity care, sensitization on misoprostol, administration of the drug, and referrals.

\subsection{Monitoring}

Monitoring data should be collected on a regular basis (either monthly or every two months) to track progress of project inputs and outputs. Monitoring forms should therefore be created to capture both input and output data. Monitoring input data should include not only details of project activities, such as training of community-based workers in misoprostol distribution or the preparation of IEC materials, but also specifics such as gender and age of recipients/participants of workshops, if relevant. Output data should include information on the beneficiaries served by the program-for example, the number of pregnant women registered by the program; the number of pregnant women who were given misoprostol; or the number and types of community mobilization activities carried out. A record of the number of tablets administered correctly and of those left over should also be kept.

Community-based workers will maintain a register where they record details of their service content, such as name, age, and address of beneficiary, service content, date and other relevant information. Registers may have to be designed and workers trained in recording data. Register data should be entered at the Council's data entry unit in the country/region. Interviewers or field staff including the community-based workers can use a separate tool to capture data from mothers during and/or after delivery (within 24-48 hours) regarding misoprostol use, perceptions about blood loss following delivery, client satisfaction, willingness to pay for misoprostol, willingness to recommend to others and to use it again, appropriateness of distribution method of misoprostol, and side effects experienced (Appendix E). 


\subsection{Process Evaluation}

Resources permitting, you should include process evaluation to assess whether the intervention is being implemented in the fashion planned. Illustrative areas for process evaluation include the content and format of training by conducting a pre-post training evaluation; assessment of knowledge retained post-training by community-based workers assessed at six-months; interviews with health workers to explore the extent of linkages between community-based workers and the health system.

At monthly meetings, trained community-based workers, Population Council staff, and any health workers involved in the project will meet to discuss barriers to administration, challenges encountered, and

Examples of Adverse Events (AEs):
-Shivering
-Fever
-Diarrhea
-Nausea
-Vomiting
-Cramping
-Postpartum bleeding
-obstructed labor
-eclampsia
Examples of Serious Adverse Events
(SAEs):
-death of mother
-death of baby

emergencies experienced in the previous month with the administration of misoprostol. The experience of the pilot program will be closely monitored and documented at every step by Population Council staff and respective government institutions and health facilities. Monitoring will include the range and frequency of project activities; who is involved in these activities and what their individual responsibilities are; when the activities occur; and, the result of each project activity. Examples of indicators used for monitoring are given in the next section. Documentation of the intervention will be produced in a report format and disseminated.

It is important to note that Adverse Events and Serious Adverse Events will be discussed at the monthly meetings and reported to the Population Council using the SAE/AE form provided (SAE Form as Appendix B). This is an important part of GCP. Program staff must undergo training in GCP from the Reproductive Health Program Director. The process to be followed if an AE or SAE is identified will be determined by the PI before the program begins.

\subsection{Illustrative Indicators}

The following table lists some illustrative indicators on areas that will be useful for the project to report on especially in terms of the feasibility of working with community-based workers. The source of data and the unit of reporting are also provided. The reference period for each type of indicator will have to be context specific depending on the length of the intervention. 


\begin{tabular}{|c|c|c|}
\hline Areas & Indicator Definition/Unit of analysis & Data Source \\
\hline Community interest and engagement & $\begin{array}{l}\text { \# of communities which have made plans for emergency transport for women } \\
\text { requiring medical help } \\
\text { \# of communities which have made other types of contributions } \\
\text { Unit: Communities }\end{array}$ & Project records \\
\hline $\begin{array}{l}\text { Knowledge of community-based } \\
\text { workers } \\
\text { When to administer Misoprostol } \\
\text { Dosage of Misoprostol } \\
\text { Side-effects of Misoprostol } \\
\text { What is an adverse event } \\
\text { What is a serious adverse event }\end{array}$ & $\begin{array}{l}\text { \% of trained community-based workers who name timing of Misoprostol } \\
\text { administration } \\
\% \text { of trained community-based workers who know the dosage of Misoprostol } \\
\% \text { of trained community-based workers who identify at least } 2 \text { side-effects } \\
\% \text { of trained community-based workers who can identify an AE } \\
\% \text { of trained community-based workers who can identify a SAE } \\
\text { Unit: Community-based workers }\end{array}$ & Post-training evaluation form \\
\hline $\begin{array}{l}\text { Interest and experience of community- } \\
\text { based workers }\end{array}$ & $\begin{array}{l}\text { \% of community-based workers still active } 9 \text { months after training } \\
\% \text { of community-based workers who were present at delivery } \\
\% \text { of community-based workers who linked with health services } \\
\text { Unit: Community-based workers }\end{array}$ & $\begin{array}{l}\text { Monitoring forms; project } \\
\text { records }\end{array}$ \\
\hline Distribution of Misoprostol & $\begin{array}{l}\text { \# of pills distributed } \\
\text { \# and \% of registered pregnant women provided Misoprostol } \\
\text { \# and \% of registered women provided Misoprostol at delivery } \\
\text { \# of times Misoprostol stock-outs occurred } \\
\text { \# of tablets not taken and returned } \\
\text { Unit: Pills; pregnant women as relevant }\end{array}$ & $\begin{array}{l}\text { Monitoring forms; project } \\
\text { records }\end{array}$ \\
\hline Knowledge and Experience of women & $\begin{array}{l}\text { \% of women who reported being contacted with community-based worker } \\
\% \text { of women who reported receiving Misoprostol from community-based } \\
\text { worker } \\
\% \text { of delivering women who were attended by both community-based worker }\end{array}$ & Interview with women \\
\hline
\end{tabular}




\begin{tabular}{|c|c|c|}
\hline & $\begin{array}{l}\text { and health worker } \\
\% \text { of women who would recommend receiving Misoprostol to others and use } \\
\text { again themselves } \\
\text { Unit: Registered pregnant women }\end{array}$ & \\
\hline $\begin{array}{l}\text { Willingness to participate in study } \\
\text { Refusal Rate } \\
\text { Timing of IC administration }\end{array}$ & $\begin{array}{l}\text { \% of women who refuse study participation of all pregnant women contacted } \\
\% \text { of women who provide consent at first contact } \\
\% \text { of women who provide consent at time of delivery } \\
\text { Unit: Pregnant women in the community }\end{array}$ & $\begin{array}{l}\text { Project Records; Monitoring } \\
\text { forms }\end{array}$ \\
\hline $\begin{array}{l}\text { Adverse events } \\
A E \\
S A E\end{array}$ & $\begin{array}{l}\text { \#of women who received Misoprostol experiencing an } A E \\
\text { \#of women who received Misoprostol experiencing an } A E \\
\text { Unit: Pregnant women in the community }\end{array}$ & $A E / S A E$ recording forms \\
\hline
\end{tabular}




\section{Useful Resources}

The resources below have been sorted into five categories. Not all of these documents were cited in this manual. Also, please be aware that several of these sources may be relevant to more than one of the below categories.

\section{WHO Statements and Consensus Documents for Best Practice}

Armbruster, Deborah. WHO Recommendations for the Prevention of Postpartum Haemorrhage. Results from a WHO Technical Consultation, October 18-20, 2006. Prevention of Postpartum Hemorrhage Initiative (POPPHI).

Armbruster, Deborah. Prevention of postpartum hemorrhage: The role of active management of the third stage of labor. POPPHI Project. International Federation of Gynecology and Obstetrics, 2006.

Blum J, Z Alfirevic, G Walraven, A Weeks, B Winikoff. Treatment of postpartum hemorrhage with misoprostol. International Journal of Gynecology and Obstetrics (2007) 99, S202-S205.

Census Statement: Instructions for Use-Misoprostol for Treatment of Incomplete Abortion and Miscarriage. Expert Meeting on Misoprostol sponsored by Reproductive Health Technologies Project and Gynuity Health Projects. June 9, 2004. New York, NY. Updated June 2008.

Gulmezoglu, AM et al. WHO Collaborative Group to Evaluate Misoprostol in the Management of the Third Stage of Labor. WHO multicentre randomized trial of misoprostol in the management of the third stage of labor. The Lancet, 2001; 358:689-95.

Huber A, Nelson D. Preventing Postpartum Hemorrhage with Active Management of the Third Stage of Labor. November 2003. (PRIME PAGES: RR-37). USAID.

International Confederation of Midwives and International Federation of Gynecology and Obstetrics. November 2003. Joint statement: Management of the third stage of labor to prevent postpartum hemorrhage.

Lalonde A, Daviss BA, Acosta A, Herschderfer K. Postpartum hemorrhage today: ICM/FIGO initiative 2004 2006. International Journal of Gynecology and Obstetrics (2006) 94, 243-253.

Prevention of Postpartum Hemorrhage Initiative. A UDAID-supported project. RTI International, PATH, EngenderHealth, International Federation of Gynecology and Obstetrics, International Confederation of Midwives. 2007.

Proposal for the Inclusion of Misoprostol in the WHO model list of essential medicines. 17th Expert committee on the selection and use of essential medicines. Geneva, March 2009. Submitted on behalf of:Gynuity Health Projects and Venture Strategies for Health.

RTI International and PATH. Prevention of Postpartum Hemorrhage Initiative (POPPHI) Project. Evaluation Report of Training Strategies for the Active Management of Third Stage of Labor. Prepared for USAID. April 2007. 
WHO, 2009. WHO Statement regarding the use of misoprostol for postpartum hemorrhage prevention and treatment. WHO/RHR/09.22. http://whqlibdoc.who.int/hq/2009/WHO RHR 09.22 eng.pdf

World Health Organization, Maternal Mortality: A Global Fact book. Geneva:1991.

WHO, UNFPA, UNICEF, and World Bank. 2000. Managing complications in pregnancy and childbirth. WHO/RHR/00.7. Geneva.

World Health Organization.2005 Make every mother and child count. The world health report. Geneva, Switzerland: WHO Press.

World Health Organization. 2009. 17th Expert Committee on the Selection and Use of Essential Medicines. Proposal for the Inclusion of misoprostol in the WHO model list of essential medicines. Geneva, March 2009. Submitted on behalf of Gynuity Health Projects and Venture Strategies for Health.

World Health Organization. Prevention and Treatment of Post-Partum Hemorrhage New Advances for Low Resource Settings. Joint Statement: ICM and FIGO. http://www.who.int/pmnch/events/2006/figo2006statementeng.pdf

\section{Service Delivery/ Country Experience}

Armbruster, Deborah. International Survey of the Management of the Third Stage of Labor. Journal of Midwifery \& Women's Health. The American College of Nurse-Midwives, 2006.

Chandhiok N, Dhillon BS, Datey S, Mathur A, Saxena NC. Oral misoprostol for prevention of postpartum hemorrhage by paramedical workers in India. International Journal of Gynecology and Obstetrics (2006) 92, 170-175.

Derman, Richard J. The role of misoprostol for prevention of postpartum hemorrhage. School of Medicine, University of Missouri: Kansas City. International Journal of Gynecology and Obstetrics (2006) 94 (Supplement 2) S131-S132.

Festin MR, Lumbiganon P, Tolosa JE, Finney KA, Ba-Thike K, Chipato T, et al. International survey on variations in practice of the management of the third stage of labor. Bull World Health Organ 2003;81:286-91.

Fullerton JT, Frick KD, Fogarty LA, Fishel JD, Vivio DM. Active Management of Third Stage Labor Saves Facility Costs in Guatemala and Zambia. Journal of Health, Population and Nutrition, Vol. 24, No. 4, Dec, 2006, pp.540 551.

Geller SE, Adams MG, Kelly PJ, Kodkany BS, Derman RJ. Postpartum hemorrhage in resource-poor settings. International Federation of Gynecology and Obstetrics, 2005.

Hawkins, Kate. 2009. Research in Focus: The role of misoprostol in making home-births safer. Future Health Systems: Innovations for equity. www.futurehealthsystems.org

Jadesimi A, Okonofua FE. Tackling the unacceptable: Nigeria approves misoprostol for postpartum hemorrhage. J Fam Plann Reprod Health Care. 2006 Oct;32(4):213-4.

Jokhio AH, Winter HR, Cheng KK. An intervention involving traditional birth attendants and perinatal and maternal mortality in Pakistan. N Engl J Med 2005;352(20):2091-9. 
Kmietowicz, Zosia. Active management reduces bleeding in third stage of labor. BMJ 1998;316:797. March 14.

Matthews Mathai et al. Saving women's lives: evidence-based recommendations for the prevention of postpartum haemorrhage. Bulletin of the World Health Organization. April 2007, 85 (4).

Miller S, Ojengbede A, Turan J, Ojengbede O, Butrick E, and Hensleigh P. Anti-Shock Garments for Obstetric Hemorrhage. Current Women's Health Reviews, 2007, 3, 3-11.

Pal, SA. Hemorrhage and Maternal Morbidity and Mortality in Pakistan. Journal of Pakistan Medical Association. 2008.

PATH, Reproductive Health Department, Ministry of Health, Vietnam. Reducing Postpartum Hemorrhage in Thanh Hoa, Viet Nam. Assessing the role of active management of third stage of labor of oxytocin in ampoules and uniject devices. Research Report, 2005.

Prendville WJ, Elbourne D, McDOnald S. Active versus expectant management in the third stage of labor [Systematic Review], vol. 2; 2005.

Ray A, Mukherjee P, Basu G. Chatterjee: misoprostol and third stage of labor. J Obstet Gynaecol India 2001;51:53-5.

Walraven G, Blum J, Dampha Y, Sowe M, Morison L, Winikoff B, Sloan N. Misoprostol in the management of the third stage of labor in the home delivery setting in rural Gambia: a randomized control trial. International Journal of Obstetrics and Gynaecology. September 2005, Vol. 112, pp. 1277-1283.

\section{Determinants/Factors associated with PPH}

Bagga, Rashmi and Vanita Jain. The impact of post-partum hemorrhage in "near-miss" morbidity and mortality in developing countries. Eur Clinics Obstet Gynecol (2006) 2: 161-169.

Chua S, Arulkumaran S, Lim I, Selamat N, Ratman SS. Influence of breastfeeding and nipple stimulation on postpartum uterine activity. Br J Obstet Gynaecol 1994;101:804-5.

Combs, Murphy, and Laros. 1991. Factors associated with postpartum hemorrhage with vaginal birth. Obstet Gynecol. 1991 Jan; 77(1):69-76.

Derman RJ, Kodkany BS, Goudar SS, Geller SE, Naik VA, Bellad MB, Patted SS, Patel A, Edlavitch SA, Hartwell T, Chakraborty H, Moss N. Oral misoprostol in preventing postpartum hemorrhage in resource-poor communities: a randomized controlled trial. Lancet 2006;368:1248-53.

El-Refaey $\mathrm{H}$ et al. The misoprostol third stage of labor study: a randomized controlled comparison between orallyadministered misoprostol and standard management. British Journal of Obstetrics and Gynaecology. September 2000, Vol 117, pp. 1104-1110.

Geller SE, Goudar SS, Adams MG, Naik VA, Patel A, Bellad MB, Patted SS, Edlavitch SA, Moss N, Kodkany BS, Derman RJ. Factors associated with acute postpartum hemorrhage in low-risk women delivering in rural India. International Journal of Gynecology and Obstetrics (2008) 101, 94-99.

Hofmeyr GJ, A Metin Gülmezoglu, Natalia Novikova, Verena Linder, Sandra Ferreira \& Gilda Piaggio. Misoprostol to prevent and treat postpartum hemorrhage; a systematic review and meta-analysis of 
maternal deaths and dose-related effects. Bulletin of the World Health Organization: Volume 87, No 9, September 2009, 645-732.

Hoj L, Cardosa P, Nelsen BB, Hvidman L, Nelsen J, Aaby P. Effect of sublingual misoprostol on severe postpartum hemorrhage in a primary health care center in Guinea-Bissau: randomized double blind clinical trial. BMJ2005;331:723.

Lagenbach C. Misoprostol in preventing postpartum hemorrhage: A meta-analysis. International Journal of Gynecology and Obstetrics (2006) 92, 10-18.

McDonald SJ, Abbott JM, Higgins SP. Prophylactic ergometrine-oxytocin versus ocytocin for the third stage of labour. Cochrane Database of Systematic Reviews 2004, Issue 1. Art. No.: CD000201. DOI: 10.1002/14651858.CD000201.pub2.

McNeilly AS, Robinson IC, Houston MH, Howie PW. Release of oxytocin and prolactin in response to suckling. Br Med J (Clin Res Ed) 1983;286:257-9.

Rogers, Jane et al. Active versus expectant management of thurd stage of labor: the Hinchingbrooke randomized controlled trial. The Lancet; Vol 351: March 7, 1998.

\section{Background Literature Review}

Blanchard K, Clark S, Winikoff B, Gaines G, Kabani G, Shannon C. Misoprostol for women's health: a review. Obstet Gynecol 2002;99:316-22.

Bugalho A, Daniel A, Faundes A, Cunha M. Misoprostol for prevention of postpartum hemorrhage. Int J Gynaecol Obstet 2001;73:1-6.

Darney PD. Misoprostol: a boon to safe motherhood ...or not? Lancet 2001;358:682-3.

Festin MR, Habana AE, Punzalan ER, Sulit MV, Kakad M. A Review of Systematic Reviews on Reducing Maternal Mortality. University of the Philippines Manila.

Fullerton JT, Thompson JB. Examining the evidence for the International Confederation of Midwives' essential competencies for midwifery practice. Midwifery (2005) 21, 2-13.

Gillespie D, Karklins S, Creanga A, Khan S, Cho N. Scaling Up Health Technologies. Prepared for the Bill \& Melinda Gates Foundation. Johns Hopkins Bloomberg School of Public Health and the Bill and Melinda Gates Institute for Population and Reproductive Health. May 2007.

Gruskin S, Cottingham J, Hilber AM, Kismodi E, Lincetto 0, Roseman MJ. Using human rights to improve maternal and neonatal health: history, connections and a proposed practical approach. Bulletin of the World Health Organization, August 2008, 86(8).

Hofmeyr GJ, Walraven G, Gulmezogu AM, Mholwana B, Alfirevc Z, Villar J. Misoprostol to treat postpartum haemorrhage: a systematic review. BJOG 2005;112:547-53.

McCormick ML, Sanghvi HC, Kinzie B, McIntosh N. Preventing postpartum hemorrhage in low-resource settings. Int J Gynaecol Obstet 2002; 77:267-75.

McDonald S. Management of the third stage of labor. J Midwifery WOmens Health 2006;52:254-62. 
Mekbib, Tekle-Ab, Annabel S Erulkar, and Sisay Melesse. Testing Delivery of Misoprostol for Postpartum Hemorrhage through Community Initiatives in rural Ethiopia: December 1 2009-November 202010. Amhara region, West Gojam and North Gondar Zones. Population Council.

Mir, Ali Mohammad and Abdul Wajid. Feasibility of Home Administration of Misoprostol in the Prevention of PPH in Rural Pakistan, May 2009-April 2010. Date Submitted to IRB: March 16, 2009. Population Council.

Said S and Geary M. Prevention of Obstetric Hemorrhage. Fetal and Maternal Medicine Review 2007; 18:3 257288.

Tsu VD, Langer A, Aldrich T. Postpartum hemorrhage in developing countries: is the public health community using the right tools? International Journal of Gynecology and Obstetrics 85 Suppl. 1 (2004) S42-S51.

Tsu VD and Shane B. New and underutilized technologies to reduce maternal mortality: call to action from Bellagio workshop. International Journal of Gynecology and Obstetrics 85 Suppl. 1 (2004) S83 S93.

\section{Useful Web Sources}

Gynuity Health Projects: http://gynuity.org/programs/postpartum-hemorrhage/

International Confederation of Midwives (ICM):

http://www.internationalmidwives.org/PostPartumHaemorrhage/tabid/339/Default.aspx

International Consortium for Medical Abortion:

http://www.medicalabortionconsortium.org/search/?cx=005634717097818635325\%3Alxcd0-

bnr0\&cof=FORID\%3A10\&ie=UTF-8\&q=misoprostol\&sa=Search\#1256

International Federation of Gynecology and Obstetrics (FIGO): http://www.figo.org/projects/prevent

(documents in English, Spanish, French and Arabic)

MAQweb: "Preventing Postpartum Hemorrhage" http://www.maqweb.org/techbriefs/tb48posthem.shtml. Last revised 2/21/08

Misoprostol in Obstetrics and Gynecology: http://www.misoprostol.org/

PATH: http://www.path.org/projects/preventing postpartum hemorrhage.php

PATH, 2005-2007. Postpartum hemorrhage. http://www.pphprevention.org/pph.php

Postpartum Hemorrhage Initiative (POPPHI): http://www.pphprevention.org/

Reproductive Health Technologies Project: $\underline{\text { ttp: }: / / w w w . r h t p . o r g / a b o r t i o n / m i s o p r o s t o l / d e f a u l t . a s p ~}$

UNFPA: Safe Motherhood: http://www.unfpa.org/mothers/statistics.htm 
US Agency for International Development:

http://www.usaid.gov/our work/global health/mch/mh/news/preventing pph.html

Venture Strategies for Health and Development: $\underline{\text { ttp://www.venturestrategies.org/publications/index.php }}$ 


\section{ANNEX 1}

Source: USAID and POPPHI. Adapted from JHPIEGO. Active Management of the Third Stage of Labor: Advances in Maternal and Neonatal Health. Available at: http://www.reproline.jhu.edu/english/2mnh/2ppts/3rdstage/3rdstagepg.htm. Accessed March 12, 2008.

\begin{tabular}{|c|c|c|c|}
\hline DRUGS & ADVANTAGES & DISADVANTAGES & DOSAGE \\
\hline Oxytocin & $\begin{array}{ll}\checkmark & \text { Highest efficacy of all available options for } \\
\checkmark & \text { PPH treatment } \\
\checkmark & \text { Acts within } 2.5 \text { minutes when given IM } \\
\checkmark & \text { No contraindications for postpartum use } \\
\checkmark & \text { More stable than ergometrine when } \\
& \text { exposed to heat/light }\end{array}$ & 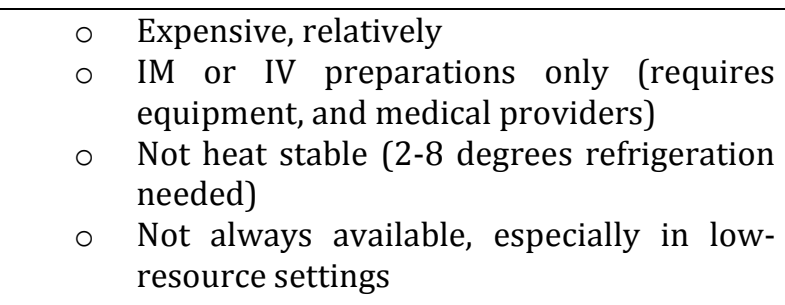 & $\begin{array}{l}10 \text { IU IM or } 5 \text { IU IV slow } \\
\text { push }\end{array}$ \\
\hline Ergometrine & $\begin{array}{ll}\checkmark & \text { Low price } \\
\checkmark & \text { Effects last 2-4 hours }\end{array}$ & $\begin{array}{ll} & \text { Takes 6-7 min to be effective through IM; } \\
\text { oral form ineffective } \\
\text { Causes tonic uterine contraction } \\
\text { Increased risk hypertension, vomiting, } \\
\text { headache } \\
\text { Contraindicated in women with } \\
\text { hypertension or heart disease } \\
\text { Not heat/light/freezing stable }\end{array}$ & $\begin{array}{l}0.2 \mathrm{mg} \text { IM } \\
\text { Note: Do not give } \\
\text { ergometrine in any form } \\
\text { to women with pre- } \\
\text { eclampsia, eclampsia or } \\
\text { high blood pressure. }\end{array}$ \\
\hline Syntometrine & $\begin{array}{l}\checkmark \quad \text { Combined effect of rapid action of oxytocin } \\
\text { and sustained effect of ergometrine }\end{array}$ & $\begin{array}{ll}\text { More expensive than ocytoxin or } \\
\text { ergometrine along } \\
\text { Same negatives as ergometrine }\end{array}$ & $\begin{array}{l}1 \mathrm{~mL} \text { IM (ergometrine } \\
0.5 \mathrm{mg}+\text { oxytocin } 5 \mathrm{IU} \text { ) }\end{array}$ \\
\hline Misoprostol & $\begin{array}{ll}\checkmark & \text { Effects last 75 min } \\
\checkmark & \text { Inexpensive } \\
\checkmark & \text { Thermo and light stable } \\
\checkmark & \text { Long shelf life (18 months at room temp) } \\
\checkmark & \text { Does not require injection skill or infection } \\
& \text { prevention measures assoc. with injection } \\
\checkmark & \text { Can be distributed at community level } \\
\checkmark & \text { No known contraindications }\end{array}$ & $\begin{array}{l}\text { Acts within } 6 \text { minutes } \\
\circ \text { Common side effects: shivering, fever, } \\
\text { nausea }\end{array}$ & $\begin{array}{l}600 \text { mcg po } \\
\\
\text { (Repeated doses of } \\
\text { misoprostol are not } \\
\text { recommended.) }\end{array}$ \\
\hline
\end{tabular}




\section{Appendix A: Alternate Solutions to Managing PPH (Geller et al 2005)}

Each solution must be carefully considered in the context of the challenges and resources that exist in the region where it is being considered for implementation.

- Natural remedies: Tea made from the leaves of the raspberry bush (Rubus ideas) has been used for centuries as a tonic that primes the uterus for efficient contraction during labor. The smooth muscle stimulant, Shepherd's purse (Capsella bursa-pastoris), increases uterine contraction and has been used in Indian Ayurvedic, Native American, and traditional Chinese medicine. Other plants, such as silk tree bark, safflower, motherwort, and yarrow, are said to have oxytocic properties to stimulate the uterus or regulate uterine blood flow. These remedies are largely anecdotal and not based on significant evidence.

- Breastfeeding and nipple stimulation: Breastfeeding immediately after delivery encourages the natural production of oxytocin and increases uterine activity. Nipple stimulation also increases uterine pressure and decreases blood loss and length of third stage labor. In areas where oxytocics are not available, breastfeeding and nipple stimulation may decrease the incidence of PPH (large randomized trials are needed).

- Anemia detection: Early detection of anemia can help in transferring high-risk cases to a higherlevel facility before delivery. Two tests, a color scale and a copper sulfate test, are available to detect anemia in the field and both tests are low cost, simple, and require brief training.

- Dietary supplementation: According to the WHO, dietary supplements for pregnant women with iron and folic acid can reduce anemia (WHO 2005).

- Early and accurate measurement of blood loss: Blood collection tools, such as Kangas in Tanzania or a special blood collection drape in India, can help accurately detect blood loss early enough to act. While some bleeding is expected after childbirth, blood loss greater than $500 \mathrm{ml}$ during the first 24 hours postpartum is commonly defined as a marker for PPH, according to the World Health Organization. 
Appendix B: Serious Adverse Event Form (Source: IND/SAE Safety Report Form Manual. April 2004, Version 2. Population Council/CRB. New York, NY)

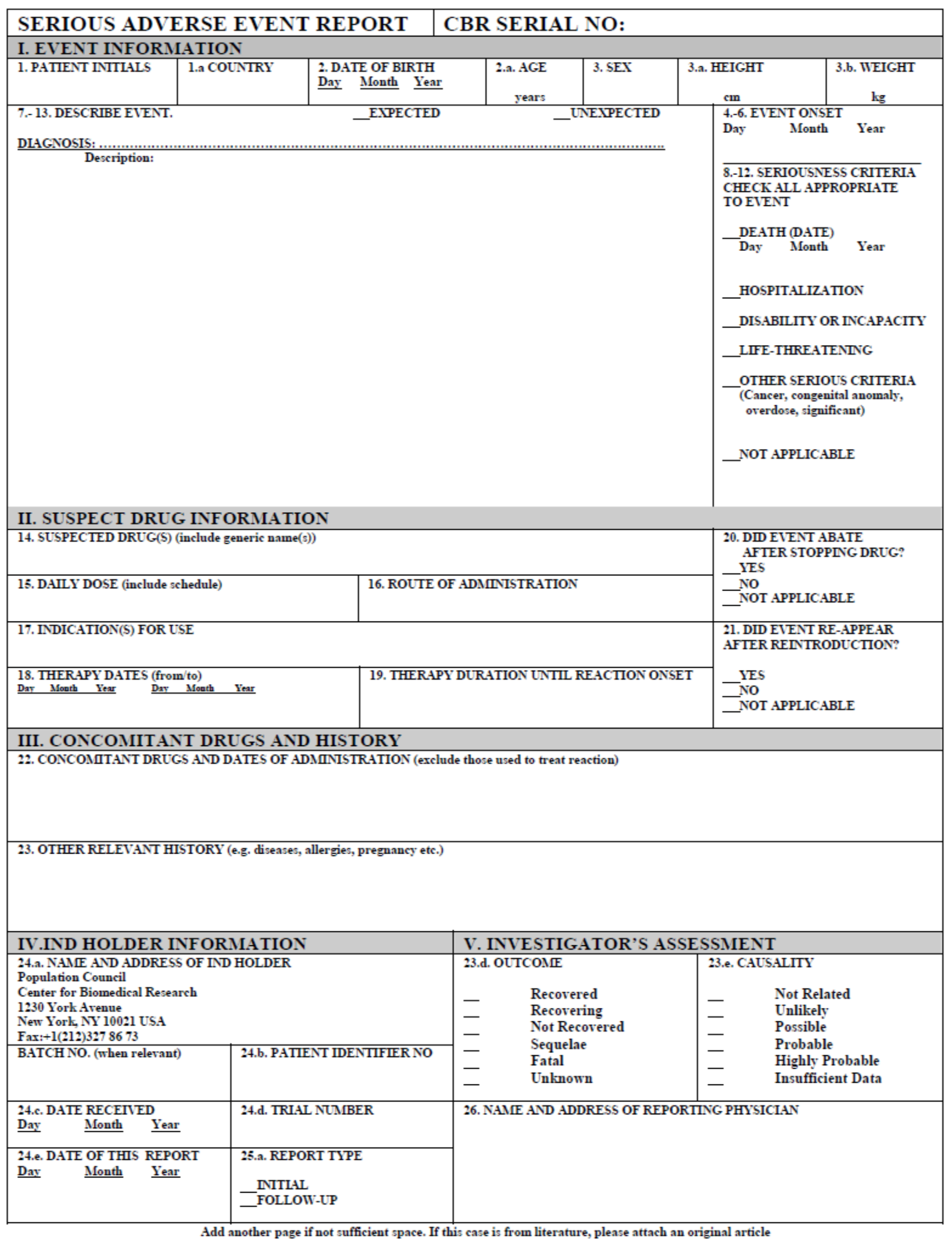




\section{Appendix C:}

Purpose: Decision Making

\section{Ethical Review Form}

This form is intended to help researchers identify some of the ethical issues surrounding proposed research involving human subjects. In particular, it should enable researchers and their supervisors to determine whether a given protocol must be submitted to the Institutional Review Board (IRB) for review.

The Population Council holds itself to the highest standards in treatment of human participants in research. This Ethical Review form is one component of the process by which the Council seeks to ensure ethical treatment of research participants. Human research ethics rest on three basic principles: respect, beneficence, and justice. These principles comprise the foundation of all regulations or guidelines governing research ethics. If you have questions on any of these issues, please review the Council Intranet Clinical Studies section or ask your supervisor.

Please note that as a requisite for publication, some journals may require IRB review prior to acceptance of a manuscript.

Date:

\section{Background}

A. Title of Proposed Research:

C. Location of Proposed Research: (City/Region, country)

B. Principal Investigator:

D. Affiliation of Principal Investigator:

E. Name and Title of Individual Submitting Form: (Council staff responsible for compliance with ethical standards and Procedures)

F. Source(s) of Funding

\section{Questions}

Please circle your response to each question. See Intranet section on "Frequently Asked Questions when Completing the Ethical Review Form" for assistance if needed.

1. Is this a clinical study by the Council's definition? (for Council's definition, go to: https://popinsider.popcouncil.org/2507 3416.htm)

Yes (go to question 10)

No (go to question 2)

2. If the study/project involves:

a. Research involving human subjects (go to question 3)

b. Research on service provision/training without involvement of human subjects (go directly to SIGNATURES section; DO NOT submit to the IRB for review)

c. Research on services or training that includes human subject participation (go to question 3)

d. Other with no human subject involvement (go directly to SIGNATURES section; DO NOT submit to the IRB)

3. Does the research involve a vulnerable study population (e.g., children, prisoners, pregnant women, handicapped, mentally disabled, homeless persons, sex workers, refugees, or those who might be discriminated against due to sexual preference?) 
Yes (go to question 10)

No (go to question 4)

4. Is this research solely involving the collection or study of existing data, documents, records, pathological or diagnostic specimens? Yes (go to question 5) No (go to question 6)

5. Is this information (i) publicly available; OR (ii) recorded by the investigator in such a manner that subjects cannot be identified, directly or through identifiers linked to the subjects? Yes (go directly to SIGNATURES section; DO NOT submit to the IRB for review) No (go to question 7)

6. Does the research involve contact with subjects based on existing confidential (e.g. medical) records of individuals who have not given prior consent? Yes (go to question 10 even if a two stage consent process is used for this study) No (go to question 7)

7. Does the collection involve physically invasive procedures (e.g. physical examination, urine and/or blood samples, pap smear)? Yes (go to question 10) No (go to question 8)

8. Would the research likely expose subjects to more than minimal: a. health risks b. legal risks c. psychological risks If yes to $8 \mathrm{a}, 8 \mathrm{~b}$, and/or $8 \mathrm{c}$ (go to question 10) If no (go to question 9 and DO NOT submit to IRB for review)

9. Please attach the Informed Consent Form (ICF) for this research. Follow the guidelines for preparation of informed consent forms, located https://popinsider.popcouncil.org/2507_2983.htm (go directly to SIGNATURES section and DO NOT submit to IRB for review)

10. Utilize the Study Protocol Template for Research Involving Human Subjects locates at https://popinsider.popcouncil.org/2507_2984.htm and submit the protocol, a copy of the Principal Investigator's completed ethical training certificate, and this completed Ethical Review Form to the IRB Administrator for IRB review.

11. Specify the name of the Population Council staff member who will represent the protocol at the IRB: 


\section{Appendix D: Model Registration Form}

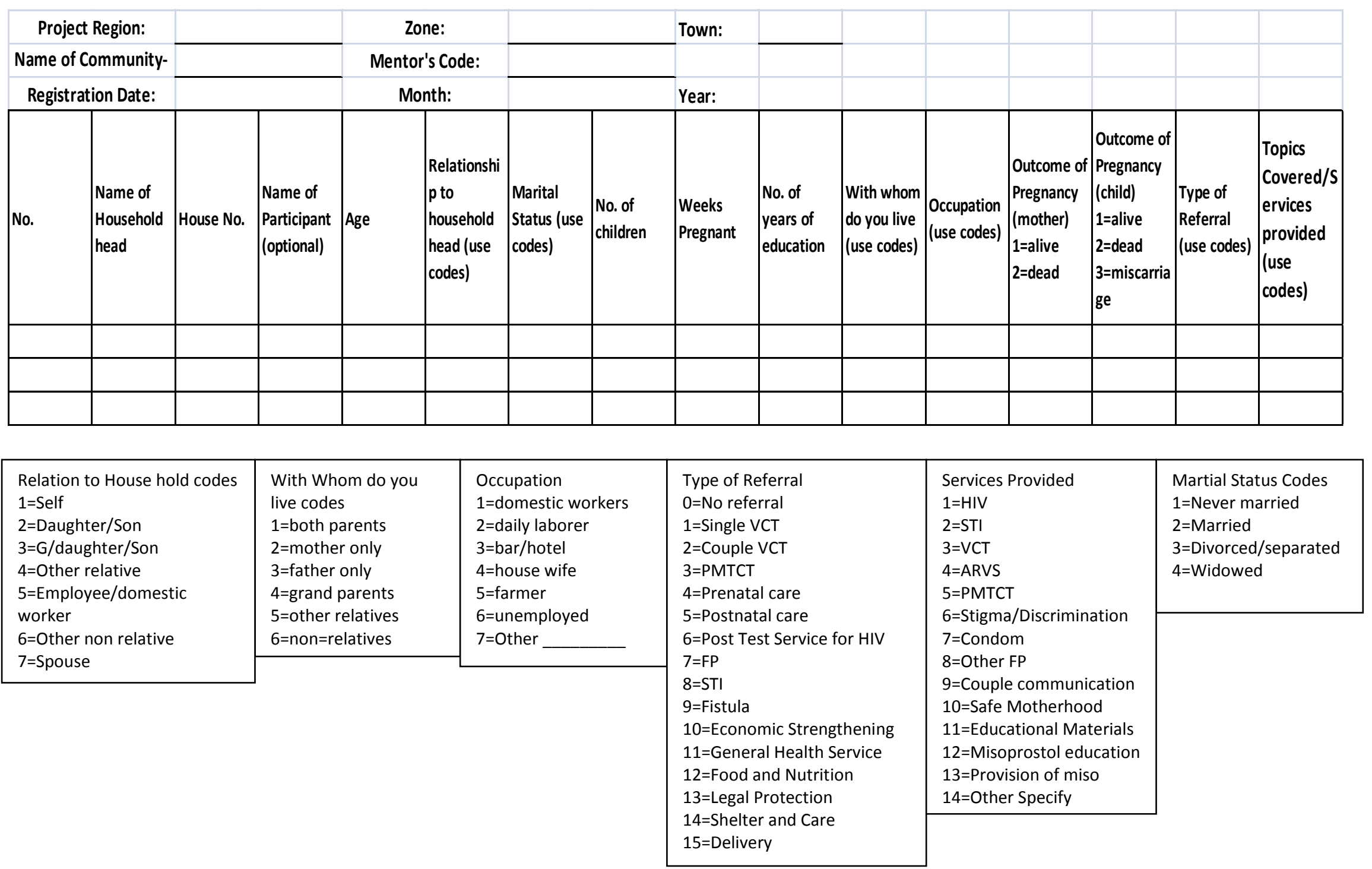




\section{Appendix E: Illustrative domains for data capture}

\section{Identification}

Region:

Name of Community-based Worker:

Date of visit to the house of the pregnant woman:

Interviews with Pregnant Women before delivery:

Socio-demographic indicators:
a. Age of the respondents
b. Education of respondents
c. Age of the husband of respondents
d. Education of the husband of respondents
e. Working status of respondents for income
f. Occupation of husband
g. Household characteristics

Information on Pregnancy:
a. Antenatal care
b. Use of supplement
c. Vaccination status
d. Information provided on PPH
e. Complication experienced at time of delivery
f. Information provided on the role of misoprostol in the prevention of PPH

\section{Interviews with women after delivery (24-48 hours):}

1. Usually, where do pregnant women deliver in your community? (home, health post, health center)

2. Where did this particular mother deliver? (own home, mother's home, mother in-laws home, health post, health center, other)

3. Have you observed this woman during labor and delivery?

4. If yes, have you provided misoprostol to prevent PPH?

5. If yes, what route did you use?

6. Was a trained community-based worker called when labor started?

7. If no, why not?

8. If yes, when was the trained community-based worker called?

9. If misoprostol not administered, explain the reasons...

10. Did mothers develop side-effects after the administration of misoprostol?

11. If yes, what were the side effects? 
12. If misoprostol was administered, but the mother continued to bleed, what measures were taken?

13. For how long did the mother bleed before she was referred?

14. What were the reasons for an urgent referral to the nearest health facility? (PPH that continued even after the administration of misoprostol, severe side effects of misoprostol, other complications)

15. What type of transportation was used to refer the patient?

16. Who paid for the transportation?

17. What was the delivery outcome?

18. Who attended the delivery?

19. Did you accompany the patient to the health facility?

20. If yes, what type of procedure was conducted to save the life of the mother? (manual removal of the placenta, blood transfusion, evacuation and curettage, hysterectomy, repair of perineal laceration, other)

21. What was the outcome of this complication (i.e. PPH)? (patient died, recovered, recovered but was anemic, required iron supplementation, recovered and needed further follow-up)

\section{Interviews with pregnant women (if referred for emergency):}

Referrals to a health facility
a. Timing of referrals
b. Reasons for referrals
c. Decision maker for referral
d. Information of complication to the LHV on back up support
e. Timing of arrival of LHV
f. Arrival at health facility
g. Management at health facility
h. Transportation used for referral cost of transportation
i. Arrival at health facility
j. Management at health facility
k. Transportation used for referral cost of transportation 